\title{
Clinical and ultrasonological features of adenomyosis and its histopathological correlation
}

\author{
Sunita Gupta, Gunjan Goel, Surabhi Agrawal*, Parul Garg, Esha Khanuja
}

Department of Obstetrics and Gynaecology, Chhatarpati Shivaji Subharti Hospital, Meerut, Uttar Pradesh, India

Received: 26 August 2016

Revised: 01 September 2016

Accepted: 06 September 2016

\section{*Correspondence:}

Dr. Surabhi Agrawal,

E-mail: drsurabhi87@gmail.com

Copyright: $\odot$ the author(s), publisher and licensee Medip Academy. This is an open-access article distributed under the terms of the Creative Commons Attribution Non-Commercial License, which permits unrestricted non-commercial use, distribution, and reproduction in any medium, provided the original work is properly cited.

\section{ABSTRACT}

Background: Adenomyosis is a common gynaecological condition that affects the menstruating women. Uterine enlargement, dysmenorrhoea and HMB are regarded as the cardinal clinical symptoms of adenomyosis. Classically it was thought, compared with ultrasonography, when adenomyosis is suspected, MRI enables more accurate diagnosis of the disease.

Methods: 78 subjects were enrolled after an informed consent that had complaints of HMB, Dysparenuia, dysmenorrhea, and chronic pelvic pain. Detailed history of the enrolled subjects was taken, followed by a clinical examination. These patients were then subjected to TVS where myometrial echo texture, presence of myometrial cysts, blurring of endomyometrial junction was noted. After hysterectomy, histopathological diagnosis was obtained.

Results: 78 subjects enrolled in the study. The mean age was 44.2 years. $43.5 \%$ had parity of 4 or more. HMB was present in $97.8 \%$ and dysmenorrhea in $93.48 \%$ of HPE positive patient. Transvaginal sonography had a sensitivity of $89.13 \%$, specificity of $90.62 \%$, positive likelihood ratio of 9.51 , negative likelihood ratio of 0.12 , positive predictive value of $93.18 \%$, negative predictive value of $85.29 \%$ and a diagnostic accuracy of $89.74 \%$.

Conclusions: Thus adenomyosis has a prevalence of $30.23 \%$. HMB with dysmenorrhoea and chronic pelvic pain helps in diagnosis. TVS is both sensitive and specific in diagnosing adenomyosis without need for additional diagnostic tool. Endomyometrial junction blurring is the sensitive and specific criteria on TVS.

Keywords: Adenomyosis, TVS, HMB

\section{INTRODUCTION}

Adenomyosis is a common gynaecological condition that affects the menstruating women. ${ }^{1}$ Bird et al defined adenomyosis as benign invasion of endometrium in to the myometrium producing a diffusely enlarged uterus which microscopically exhibits ectopic, non-neoplastic endometrial glands and stroma surrounded by hypertrophic and hyperplastic myometrium. ${ }^{2}$ Uterine enlargement, dysmenorrhoea and menorrhagia are regarded as the cardinal clinical symptoms of adenomyosis. ${ }^{3,4}$

It is relatively frequent in multiparous women, in their fourth and fifth decade of life. ${ }^{5}$ Risk factors for adenomyosis are age, multiparity, surgical disruption of the endometrial-myometrial border, elevated levels of both FSH and prolactin, smoking habits and history of depression. ${ }^{6,7}$ Because symptoms of adenomyosis closely mimic those of other uterine pathology such as leiomyoma, endometriosis or endometrial polyps, clinical diagnosis is challenging. ${ }^{8,9}$

The sonographic findings in adenomyosis include presence of myometrial hypoechoic striations or myometrial cyst or heterogeneous areas, asymmetry of myometrial wall, diffuse vascularity and globular uterine configuration. The evaluation of junctional zone (JZ) by sonography is imprecise due to difficulty in obtaining optimal views to differentiate between the inner and the 
outer myometrium. 2D sonography reports only the subjective impression of a poorly defined junctional zone with low sensitivity, but with 3D sonography having coronal sections, JZ may be visualized more clearly. ${ }^{10}$ Classically it was thought, compared with ultrasonography, when adenomyosis is suspected, MRI enables more accurate diagnosis of the disease. ${ }^{11}$

\section{METHODS}

The study was conducted in the department of Obstetrics and Gynaecology, Subharti medical college and hospital, Meerut, India over a period of two years. A total of 172 subjects were enrolled in the study who presented with the following chief complaints: Heavy menstrual bleeding (HMB), Dyspareunia, Dysmenorrhea, Chronic pelvic pain. Those excluded were: Post-menopausal, on GnRH analogues, pregnant, genital malignancy, pelvic organ prolapse, not planned for hysterectomy.

Thus, 72 subjects were excluded from the study as per the exclusion criteria.

A questionnaire was prepared and a detailed history of enrolled subjects regarding age, marital status, education status, occupation, personal history, obstetrical history (especially h/o spontaneous abortion, preterm labour), menstrual history and history of any previous procedure done on uterus (dilatation and curettage, caesarean and myomectomy), contraception used, any medical treatment taken to control heavy menstrual flow or dysmenorrhoea was taken.

Following history, a detailed clinical examination was done which included a General Physical Examination, Systemic examination, Per speculum examination and a Per vaginal and bimanual examination was done. Candidates enrolled in the study were subjected to 2D Transvaginal sonography. 22/100 subjects did not give consent for participation in study due to personal reasons. Thus study was done on 78 subjects.

\section{Transvaginal ultrasonography}

We observed the size and shape of the uterus, myometrial echo texture, presence of myometrial cysts, blurring of endomyometrial junction and presence of any associated adnexal pathology. Following this, the patients were subjected to hysterectomy after a pre-anesthetic examination and specimen was sent for histopathological examination.

\section{Statistical analysis}

The data was compiled in a standardized case record form for 78 subjects and statistical analysis was done.

Categorical variables were presented in number and percentage $(\%)$ and continuous variables were presented as mean \pm SD and median. Normality of data was tested by Kolmogorov-Smirnov test. If the normality was rejected then non parametric test was used. Odds ratio with 95\% Confidence Intervals calculated for selected variables and their significance tested. Statistical tests applied were as follows:

1. Quantitative variables were compared using unpaired t-test/Mann-Whitney Test (when the data sets were not normally distributed) between the two groups.

2. Qualitative variables were compared using ChiSquare test /Fisher's exact test.

3. Diagnostic test was used to calculate sensitivity, specificity, negative predictive value (NPV) and positive predictive value (PPV) of various factors with respect to histopathology findings.

\section{RESULTS}

A total of 172 subjects planned for hysterectomy agreed to participate in our study done. 72 subjects were excluded from the current study, as they did not meet our inclusion criteria. Out of the remaining 100 subjects, 22 later refused for enrolment. 6 of these 22 cases had adenomyosis. Thus statistical analysis was done on 78 participants. 46/78 women had histologically-proven adenomyosis. Out of a total of 172 hysterectomies we had 52 women $(30.23 \%)$ with histopathologically- proven adenomyosis. The most common indication for hysterectomy was prolapse. 55/172 (31.97\%). The mean age of subjects with adenomyosis in our study came out to be $44.2 \pm 3.9$ years. $43.47 \% \quad(20 / 46)$ of our histopathologically positive subjects had parity 4 or more. Association of history of previous surgeries on uterus with adenomyosis was analysed statistically. No statistically significant association was found. With dilatation and curettage, myomectomy and caesarean section.

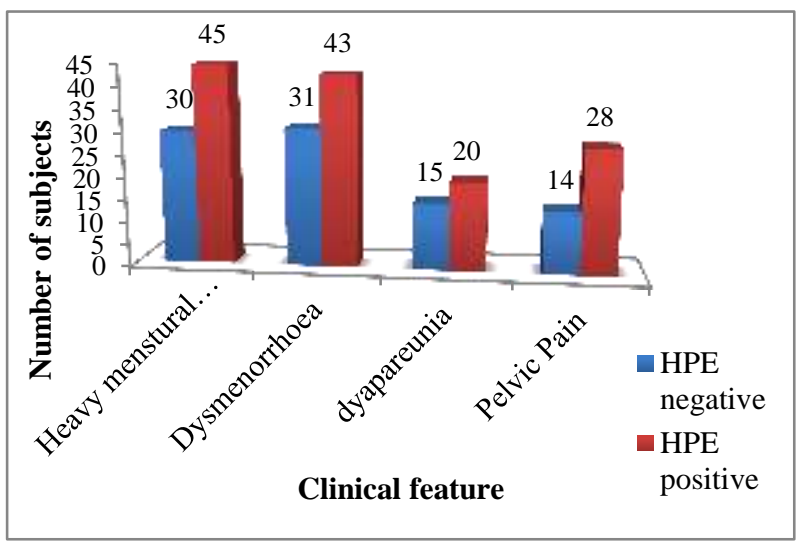

Figure 1: Comparison of symptoms in subjects included in the study.

The presenting complaints of the 78 subjects were recorded (Figure 1). The clinical features were correlated with the histopathological findings. Their sensitivity, specificity, positive likelihood ratio, negative likelihood 
ratio, positive predictive value, negative predictive value and diagnostic accuracy are shown in Table 1 and 2 and line diagram of same has been depicted in Figure 2. Among all the clinical features heavy menstrual bleeding had the highest sensitivity, diagnostic accuracy and lowest negative likelihood ratio while chronic pelvic pain had the highest specificity and positive likelihood ratio and positive predictive value. HMB had the highest odds ratio indicating that subjects with these symptoms had the highest risk of having adenomyosis. $\mathrm{P}$ value was not statistically significant for any clinical features.

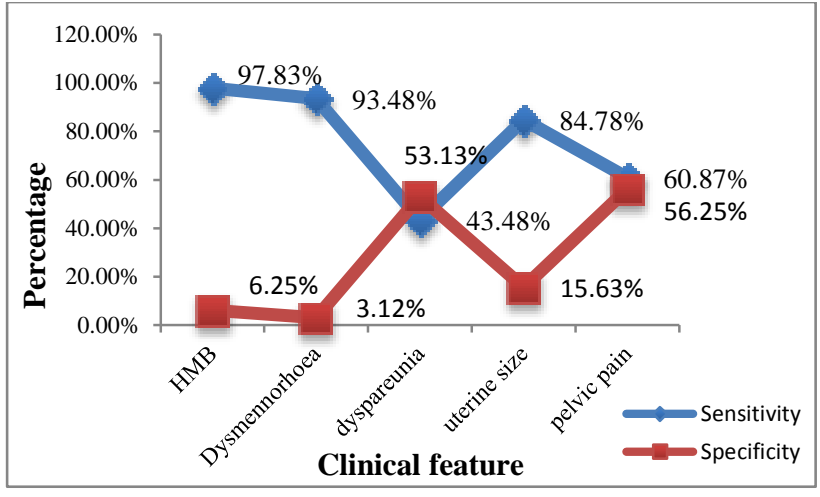

Figure 2: Sensitivity and specificity of the clinical features.

Table 1: Statistical analysis of different features of Adenomyosis.

\begin{tabular}{|lllllllll|}
\hline Clinical feature & Total & Sensitivity & Specificity & + LR & -LR & PPV & NPV & Diagnostic accuracy \\
\hline HMB & $45 / 46$ & $97.83 \%$ & $6.25 \%$ & 1.04 & 0.35 & $60.00 \%$ & $66.67 \%$ & $60.25 \%$ \\
\hline Dysmennorhoea & $43 / 46$ & $93.48 \%$ & $3.12 \%$ & 0.96 & 2.09 & $58.11 \%$ & $25.00 \%$ & $56.41 \%$ \\
\hline Dyspareunia & $20 / 46$ & $43.48 \%$ & $53.13 \%$ & 0.93 & 1.06 & $57.14 \%$ & $39.53 \%$ & $47.44 \%$ \\
\hline Uterine size, $\geq 8$ weeks & $39 / 46$ & $84.78 \%$ & $15.63 \%$ & 1 & 0.97 & $59.09 \%$ & $41.67 \%$ & $56.41 \%$ \\
\hline Chronic pelvic pain & $28 / 46$ & $60.87 \%$ & $56.25 \%$ & 1.39 & 0.7 & $66.67 \%$ & $50.00 \%$ & $58.97 \%$ \\
\hline
\end{tabular}

Table 2: $P$ values of different clinical features of adenomyosis.

\begin{tabular}{|lll|}
\hline Presenting complaint & Odds ratio & P value \\
\hline Heavy menstrual bleeding & 3 & 0.378 \\
\hline Dysmenorrhoea & 0.462 & 0.513 \\
\hline Dysparunia & 0.872 & 0.767 \\
\hline Uterine size $>8$ weeks & 0.969 & 0.961 \\
\hline Uterine size $>8$ weeks & 0.969 & 0.961 \\
\hline Chronic pelvic pain & 2 & 0.138 \\
\hline
\end{tabular}

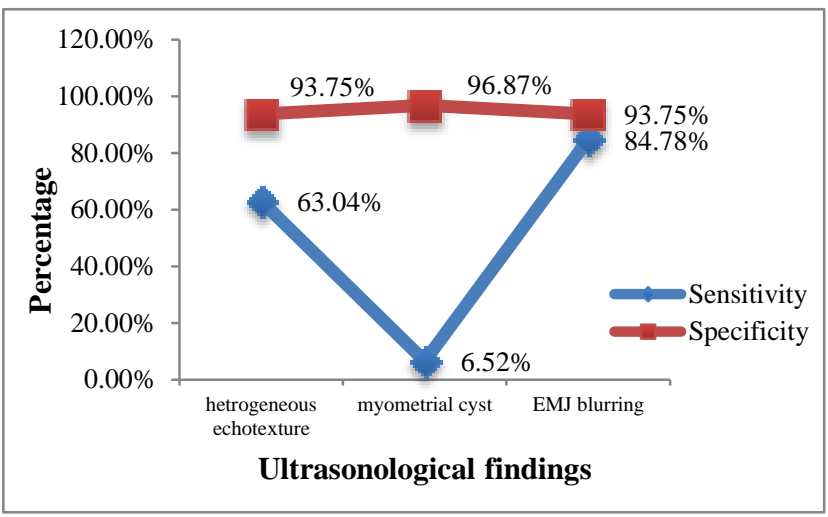

Figure 3: Sensitivity and specificity of various ultrasonological features of adenomyosis.

Transvaginal sonography of all subjects included in the study was done. Sonological features such as presence of heterogeneous echotexture, myometrial cysts and endomyometrial junction blurring was noted (Table 3-5). Among the features considered endomyometrial junction blurring had the highest sensitivity, positive predictive value, negative predictive value and diagnostic accuracy. Myometrial cyst had the highest specificity. Endomyometrial junction blurring and heterogenous echotexture had significant $\mathrm{p}$ value. Thus transvaginal sonography had a sensitivity of $89.13 \%$, specificity of $90.62 \%$, positive likelihood ratio of 9.51 , negative likelihood ratio of 0.12 , positive predictive value of $93.18 \%$, negative predictive value of $85.29 \%$ and a diagnostic accuracy of $89.74 \%$.

Table 3: Ultrasound findings compared to histopathology findings.

\begin{tabular}{|llll|}
\hline & $\begin{array}{l}\text { TVS } \\
\text { showing } \\
\text { adenomyosis }\end{array}$ & $\begin{array}{l}\text { TVS not } \\
\text { showing } \\
\text { adenomyosis }\end{array}$ & Total \\
\hline $\begin{array}{l}\text { HPE } \\
\text { showing } \\
\text { adenomyosis }\end{array}$ & $\begin{array}{l}41 \\
\text { (true positive) }\end{array}$ & $\begin{array}{l}5 \\
\text { (false negative) }\end{array}$ & 46 \\
\hline $\begin{array}{l}\text { HPE not } \\
\text { showing } \\
\text { adenomyosis }\end{array}$ & $\begin{array}{l}\text { (false positive) } \\
\text { (true negative) }\end{array}$ & 32 \\
\hline & 44 & 34 & 78 \\
\hline
\end{tabular}


Table 4: Statistical parameters of ultrasonographic features of adenomyosis.

\begin{tabular}{|llllllll|}
\hline Ultrasonological feature & Sensitivity & Specificity & + LR & -LR & PPV & NPV & Diagnostic accuracy \\
\hline Heterogeneous echotexture & $63.04 \%$ & $93.75 \%$ & 10.09 & 0.39 & $93.55 \%$ & $63.83 \%$ & $75.64 \%$ \\
\hline Myometrial cyst & $6.52 \%$ & $96.87 \%$ & 2.09 & 0.96 & $75.00 \%$ & $41.89 \%$ & $43.59 \%$ \\
\hline $\begin{array}{l}\text { Endomyometrial junction } \\
\text { blurring }\end{array}$ & $84.78 \%$ & $93.75 \%$ & 13.57 & 0.16 & $95.12 \%$ & $81.08 \%$ & $88.46 \%$ \\
\hline
\end{tabular}

Table 5: Odd ratio and $p$ value of ultrasonographic features.

\begin{tabular}{|lll|}
\hline Hetrogenous echotexture & $<0.0005$ & 25.588 \\
\hline Myometrial cyst & 0.513 & 2.163 \\
\hline $\begin{array}{l}\text { Endomyometrial junction } \\
\text { blurring }\end{array}$ & $<0.0005$ & 83.571 \\
\hline
\end{tabular}

\section{DISCUSSION}

Adenomyosis is still largely under diagnosed preoperatively as it has no specific signs and symptoms of its own. In our study the histological prevalence of adenomyosis was $30.2 \% \quad(52 / 172)$. The reported prevalence of adenomyosis varies widely; from 5 to $70 \% .^{12}$ This wide range reflects differences in patient population, histopathological criteria used to diagnose adenomyosis and the diligence with which pathology specimens are examined. ${ }^{13-15}$

The histological prevalence of adenomyosis in our study falls within the reported range; however the actual prevalence may have been over or under estimated depending on how thoroughly the pathologists examined the hysterectomy specimens.

In our study the number of sections taken varied according to the pathologist doing the examination and the gross pathology seen in the uterus. On average two sections are taken from the anterior and posterior myometrial walls for diagnosis of adenomyosis, but we did not standardize the number of histological uterine sections for this study. Bird et al demonstrated that when pathologists took three routine sections, the prevalence of adenomyosis was $31 \%$ and when the sections increased to six, the prevalence increased to $61 \%$. The prevalence of adenomyosis in various studies is shown in Table $6 .{ }^{2}$

Table 6: Prevalence of adenomyosis in various studies.

\begin{tabular}{|c|c|c|c|}
\hline${\text { Moghadam et } \mathbf{a l}^{16}}^{16}$ & 2006 & 135 & $20.26 \%$ \\
\hline Exacoustos et al $^{17}$ & 2011 & 72 & $44.4 \%$ \\
\hline 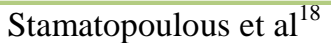 & 2012 & 135 & $19.26 \%$ \\
\hline Shrestha et al ${ }^{19}$ & 2012 & 150 & $52 \%$ \\
\hline Current study & 2014 & 172 & $30.2 \%$ \\
\hline
\end{tabular}

\section{Age}

Adenomyosis is a disease of reproductive age. The mean age of subjects with adenomyosis in our study came out to be $44.2 \pm 3.9$ years, which was inconsistent with the other studies done by, Exacoustos et al Shresta et al and Levgur et al, who found mean age at adenomyosis to be $46.5 \pm 1.5,46.7$ and $45.8 \pm 8.3$ years respectively and in contrast to the study by Bazot, whose mean age at adenomyosis was $51 .^{17,19-21}$

\section{Parity}

$43.47 \%(20 / 46)$ of our histopathologically positive subjects had parity 4 or more. This was in accordance with other studies. Bird et al reported that the average parity of women with adenomyosis was 3.2.2 Shaikh and khan had $56.8 \%$ of cases having parity greater than 422 , whereas Kunz et al and Vavilis et al, Taran et al and shrestha et al also stated that multiparity was associated with adenomyosis. ${ }^{5,7,19,23}$ It has been postulated that stress of labour and delivery which causes endometrial damage and subsequent uterine repair allow the lining cells to invade the muscle wall (Shrestha et al). ${ }^{19}$ However adenomyosis have also been reported in nulliparous women too.

\section{History of previous surgeries on uterus}

In the current study it was found history of caesarean, dilatation and curettage and myomectomy does not predispose to adenomyosis. It was in accordance with other studies. Benson and Sneedon, Bird et al and Haris et al in their study concluded that obesity and prior caesarean section are not predisposing factors for adenomyosis. $^{24-26}$ Spontaneous miscarriage has been observed more frequently in women with adenomyosis uteri. Sharp curettage during termination of pregnancy or following early pregnancy loss increases the risk possibly by disrupting the endometrial-myometrial interface and facilitating embedding of the endometrium within the myometrium. ${ }^{27}$ This practice has largely been superseded by suction curettage. Interestingly, sharp curettage of the nonpregnant uterus does not increase the risk of uterine adenomyosis. 


\section{Clinical features}

Clinically, more than $95 \%$ of women with adenomyosis presented with dysmenorrhea and heavy menstrual bleeding.

In the present study, we found heavy menstrual bleeding was present in $97.83 \%$ subjects, $60.87 \%$ had chronic pelvic pain, $93.48 \%$ had dysmenorrhea, $43.48 \%$ had dyspareunia and $84.78 \%$ had a uterine size of $\geq 8$ weeks on clinical examination, thus indicating that our study was inconsistent with other studies which used the classical triad of uterine enlargement, dysmenorrhea and menorrhagia for the diagnosis of adenomyosis (Table 1).

Bird et al found $51.2 \%$ of patients with adenomyosis complained of menorrhagia. $^{2}$ In his review Matalliotakis et al noted that the adenomyotic uterus has been described as globular or boggy but rarely exceeding 12 weeks gestation in size. ${ }^{28}$ Taran et al conducted a study on 85 subjects and found that heavy menstrual bleeding was present in $50.6 \%$ and menorrhagia with dyspareunia in $12.4 \%$.

Exacoustos et al reported pain and bleeding as symptoms typical of adenomyosis, but also stated that many women remain asymptomatic. ${ }^{17}$ Shestha et al in their study on 78 women found that heavy menstrual bleed was present in $78.2 \%$ along with chronic pelvic pain $76.9 \%$. Dysmenorrhoea and dyspareunia was present in $73.1 \%$ and $24.4 \%$ of subjects respectively. They also found that enlarged uterus was present in $70.5 \%$ of subjects whereas only $29.5 \%$ of subjects had normal size of uterus on clinical examination. ${ }^{19}$ Similarly Levy et al reported that $1 / 3^{\text {rd }}$ of patients are asymptomatic, and when there are functional signs, they remain non-specific, consisting mainly of menometrorhagia, dysmenorrhoea and pelvic pain. $^{29}$

\section{Ultrasonography}

Adenomyosis is a debilitating disease affecting women of the reproductive age group. Earlier it was difficult to diagnose the condition pre-operatively due to lack of diagnostic modalities and thus a diagnosis of adenomyosis was made by histopathology at the time of hysterectomy only, but now with the changing scenario and easy availability of ultrasonography in gynaecology, incidence of pre-operative diagnosis of adenomyosis is on the rise. Transvaginal sonography is thus a cost effective, minimally invasive and readily available tool for obstetrician and gynaecologist. ${ }^{9}$

Table 7: Comparison of statistical parameters of TVS for diagnosis of adenomyosis between previous and index study.

\begin{tabular}{|c|c|c|c|c|c|c|}
\hline Study & Year & Number of patients & Sensitivity & Specificity & PPV & NPV \\
\hline Fedele et $\mathrm{al}^{30}$ & 1992 & 34 & 86.6 & 57.9 & 61.9 & 84.6 \\
\hline Ascher et al ${ }^{31}$ & 1994 & 17 & 52.9 & 66.6 & 90 & 20 \\
\hline Reinhold et $\mathrm{al}^{32}$ & 1995 & 100 & 86 & 86 & 71 & 94 \\
\hline Brosens et al ${ }^{33}$ & 1995 & 34 & 86.6 & 50 & 86 & 77 \\
\hline Bazot et $\mathrm{al}^{21}$ & 2001 & 120 & 65 & 97.5 & 92.8 & 88.8 \\
\hline Kepkep et al $^{8}$ & 2007 & 70 & 80.8 & 61.4 & 55.3 & 84.4 \\
\hline Dueholm et al ${ }^{34}$ & 2007 & 102 & 83 & 67 & 50 & 91 \\
\hline Current study & 2015 & 78 & 89.1 & 90.6 & 93.2 & 85.3 \\
\hline
\end{tabular}

Table 8: Statistical comparison of various TVS features between previous and index study.

\begin{tabular}{|c|c|c|c|c|c|c|c|c|}
\hline TVS finding & Study & Sensitivity & Specificity & PPV & NPV & $+\mathrm{LR}$ & -LR & Accuracy \\
\hline \multirow{4}{*}{ Myometrial cyst } & Exacoustis $^{11}$ & 53 & 98 & 84 & 72 & 21.3 & 0.48 & 78 \\
\hline & Bazot et al ${ }^{15}$ & 80 & 98.8 & 96 & 83.2 & - & - & 84.2 \\
\hline & Kepkep et al ${ }^{31}$ & $61.5 \%$ & $81.8 \%$ & $66.7 \%$ & $78.3 \%$ & - & - & $74.3 \%$ \\
\hline & Current & 6.52 & 96.87 & 75 & 41.9 & 2.09 & 0.96 & 43.6 \\
\hline \multirow{4}{*}{$\begin{array}{l}\text { Hetrogenous } \\
\text { echotexture }\end{array}$} & Exacoustis et al ${ }^{11}$ & 88 & 65 & 67 & 87 & 2.5 & 0.19 & 75 \\
\hline & ${\text { Bazot et } \mathrm{al}^{15}}^{15}$ & 52.5 & 90 & 33.8 & 40.1 & - & - & 90 \\
\hline & Kepkep et al ${ }^{31}$ & 80.8 & 61.4 & 55.3 & 84.4 & - & - & 68.6 \\
\hline & Current & 63 & 93.8 & 93.6 & 63.8 & 10.1 & 0.39 & 75.6 \\
\hline \multirow{3}{*}{ Overall } & Exacoustis $^{11}$ & 75 & 90 & 86 & 82 & 7.5 & 0.28 & 83 \\
\hline & Bazot $^{15}$ & 65 & 97.5 & 92.8 & 88.8 & 86.6 & - & \\
\hline & Kepkep et al ${ }^{31}$ & 80.8 & 61.4 & 55.3 & 84.4 & - & - & 68.6 \\
\hline
\end{tabular}


Current study, using 2D transvaginal sonography reported a sensitivity of $89.1 \%$, specificity of $90.62 \%$, PPV of $93.18 \%$, NPV of $85.29 \%$, +LR 9.51\%, -LR $0.12 \%$ and a diagnostic accuracy of $89.74 \%$ for preoperative diagnosis of adenomyosis. These parameters were compared with other studies and are tabulated in the table below (Table 7).

The sensitivity $(89.1 \%)$ in our study was better than that reported by Bazot et al $(65 \%)$ and Ascher et al $(52.9 \%){ }^{21,31}$ A high specificity $(90.6 \%)$ was noted in the index study which was similar to studies by Reinhold et al, Bazot et al, Kepkep et al, Dueholm et al and Ascher et al and in contrast to study by Fedele et al and Brosens et al. ${ }^{8,21,30-34}$ The ultrasound criteria used in the index study for diagnosis of cysts and endomyometrial junction blurring, of which the most sensitive parameter was blurring of endomyometrial junction (84.78\%) and the most specific parameter for diagnosis came out to be presence of myometrial cysts $(96.87 \%)$.

This was similar to studies by Exacoustus et al and Bazot et al. ${ }^{17,21}$ The various ultrasonography features of various studies with the index study have been compared in Table 8.

The variable diagnostic performance of TVS for the diagnosis of adenomyosis reported in the literature could be explained by differences in diagnostic criteria used in various studies. The main criteria used for diagnosing adenomyosis on USG wasthe presence of heterogeneous myometrial echotexture. ${ }^{31}$ It was thought that this represented myometrial smooth muscle hyperplasia and hypertrophy reaction due to presence of ectopic endometrial glands within the myometrium. ${ }^{19,29}$

In the index study myometrial cysts had lowest sensitivity $(6.52 \%)$ and highest specificity. Thus from the index study it was concluded that the absence of the myometrial cysts does not rule out the disease but its presence is highly suggestive of adenomyosis.

\section{Funding: No funding sources}

Conflict of interest: None declared

Ethical approval: The study was approved by the Institutional Ethics Committee

\section{REFERENCES}

1. Tamai K, Koyama T, Umeoka S, Saga T, Fujii S, Togashi K. Spectrum of MR features in adenomyosis. Best Practice and Research. Clin Obstetr Gynaecol. 2006:20(4):583-602.

2. Bird C, McElin T, Manalo-Estrella P. The elusive adenomyosis of the uterus-revisited. Am J Obstetr Gynecol. 1972;112(5):583-93.

3. Mehasseb MK, Habiba MA. review adenomyosis uteri: an update. The Obstetr Gynaecol. 2009;11:417.
4. Bergholt T, Eriksen L, Berendt N, Jacobsen M, Hertz JB. Prevalence and risk factors of adenomyosis at hysterectomy. Human Reprod. 2001;16(11):2418-21.

5. Kunz G, Beil D, Deininger H, Wildt L, Leyendecker G. The dynamics of rapid sperm transport through the female genital tract: evidence from vaginal sonogram of uterine peristalsis and hysterosalpingoscintigraphy. Human Reprod. 1996;11(3):627-32.

6. Parazzini F, Mais V, Cipriani S, Busacca M, Venturini P; GISE. Determinants of adenomyosis in women who underwent hysterectomy for benign gynecological conditions: results from a prospective multicentric study in Italy. Eur J Obstet Gynecol Reprod Biol. 2009;143(2):103-6.

7. Taran FA, Weaver AL, Coddington CC, Stewart EA. Understanding adenomyosis: a case control study. Fertility and Sterility. 2010;94:1223-8.

8. Kepkep K, Tuncay G, Göynümer, Tutal E. Transvaginal sonography in the diagnosis of adenomyosis: which findings are most accurate? Ultrasound in Obstetr Gynecolol. 2007;30:341-5.

9. Meredith SM, Ramos LS, Kaunitz AM. Diagnostic accuracy of transvaginal sonography for the diagnosis of adenomyosis: systematic review and metaanalysis. Am J Obstetr Gynecol. 2009;201107.e1-6.

10. Devlieger R, D'Hooge T, Timmerman D. Uterine adenomyosis in the infertility clinic. Human Reprod Update. 2003;9(2):139-47.

11. Benagiano G, Brosens I. History of Adenomyosis. Best Pract Res Clin Obstetr Gynaecol. 2006;20(4):449-63.

12. Leyendecker G, Wildt L, Mall G. The pathophysiology of endometriosis and adenomyosis: tissue injury and repair. Arch Gynecol Obstetr. 2009;280:529-38.

13. Bergholt T, Eriksen L, Berendt N, Jacobsen M, Hertz JB. Prevalence and risk factors of adenomyosis at hysterectomy. Human Reprod. 2001;16(11):2418-21.

14. Bazot M, Daraï E, Rouger J, Detcher R, Cortez A, Uzan S. Limitations of transvaginal sonography for the diagnosis of adenomyosis with histopathological correlation. Ultrasound in Obstetr Gynecol. 2002;20:605-11.

15. Atri M, Reinhold C, Mehio A, Chapman W. Patrice M. Adenomyosis: US features with histolohic correlation in an in vitro study. Radiol. 2000;215:783-90.

16. Moghadam R, Lathi RB, Shahmohamady B, Saberi NS, Nezhat CH, Nezhat F, et al. Predictive value of magnetic resonance imaging in differentiating between leiomyoma and adenomyosis. JSLS. 2006;10(2):216-9.

17. Exacoustos C, Brienza L, Di Giovanni A, Szabolcs B, Romanini ME, Zupi E, et al. Adenomyosis: threedimensional sonographic findings of the junctional zone and correlation with histology. Ultrasound Obstet Gynecol. 2011;37(4):471-9. 
18. Stamatopoulos CP, Mikos T, Grimbizis GF, Dimitriadis AS, Efstratiou I, Stamatopoulos P, et al. Value of magnetic resonance imaging in diagnosis of adenomyosis and myomas of the uterus. J Minim Invasive Gynecol. 2012;19(5):620-6.

19. Shrestha A. Risk factors for adenomyosis. J Nepal Health Res Counc. 2012;10(22):229-33.

20. Levgur M, Abadi M, Tucker A. Adenomyosis: symptoms, histology, and pregnancy terminations. Obstetr Gynecol. 2000;95(5):688-91.

21. Bazot M, Cortez A, Darai E, Rouger J, Chopier J, Antoine JM, et al. Ultrasonography compared with magnetic resonance imaging for the diagnosis of adenomyosis: correlation with histopathology. Hum Reprod. 2001;16(11):2427-33.

22. Shaikh H, Khan KS. Adenomyosis in Pakistani women: four year experience at the Aga Khan University Medical Centre, Karachi. J Clin Pathol. 1990;43(10):817-9.

23. Vavilis D, Agorastos T, Tzafetas J. Adenomyosis at Hysterectomy: prevalence and relationship to operative findings and reproductive and menstrual factors. Clin Experiment Obstetr Gynecol. 1996;53:36-8.

24. Benson R, Sneeden V. Adenomyosis: a reappraisal of symptomatology. Am J Obstet Gynecol. 1958;76:6132-6.

25. Harris WJ, Daniell JF, Baxter JW. Prior cesarean section. A risk factor for adenomyosis? J Reprod Med. 1985;30(3):173-5.

26. Ferenczy A. Pathophysiology of adenomyosis. Hum Reprod Update. 1998;4(4):312-22.

27. Vercellini P, Vigano P, Somigliana E, Daguati R, Abbiati A, Fedele L. Adenomyosis: epidemiological factors. Best Practi Res Clin Obstetr Gynaecol. 2006;20(4):465-77.
28. Matalliotakis IM, Kourtis AI, Panidis DK. Adenomyosis. Obstetr Gynecolol Clin North America. 2003;30:63-82.

29. Levy G, Dehaene A, Laurent N, Lernout M, Collinet $\mathrm{P}$, Lucot JP, et al. An update on adenomyosis. Diagn Interv Imaging. 2013;94(1):3-25.

30. Fedele L, Bianchi S, Dorta M, Arcaini L, Zanotti F, Carinelli S. Transvaginal ultrasonography in the diagnosis of diffuse adenomyosis. Fertility and Sterility. 1992;58:94-7.

31. Ascher SM, Arnold LL, Patt RH, Schruefer JJ, Bagley AS, Semelka RC, et al. Adenomyosis: prospective comparison of MR imaging and transvaginal sonography. Radiology. 1994;190:8036.

32. Reinhold C, Atri M, Mehio A, Zakarian R, Aldis A, Bret P. Diffuse Uterine Adenomyosis: Morphologic Criteria. Diagnostic Accuracy of Endovaginal Sonography. Radiology. 1995;197(3):609-14.

33. Brosens JJ, de Souza NM, Barker FG, Paraschos T, Winston RM. Endovaginal ultrasonography in the diagnosis of adenomyosis uteri: Identifying the predictive characteristics. $\mathrm{Br} \mathrm{J}$ Obstet Gynaecol. 1995;102(6):471-4.

34. Dueholm M, Lundorf E. Transvaginal ultrasound or MRI for diagnosis of adenomyosis. Curr Opin Obstet Gynecol. 2007;19(6):505-12.

Cite this article as: Gupta S, Goel G, Agrawal S, Garg P, Khanuja E. Clinical and ultrasonological features of adenomyosis and its histopathological correlation. Int J Reprod Contracept Obstet Gynecol 2016;5:3283-9. 